\title{
Thermally induced brine migration in salt
}

\author{
MARTIN DANGELMAYR ${ }^{1}$, HAKIM BOUKHALFA $^{1}$, FLORIE $^{2}$ \\ CAPORUSCIO $^{1}$, PHILliP STAUFFER ${ }^{2}$ \\ ${ }^{1}$ Earth Systems Obs., Los Alamos National Laboratory \\ ${ }^{2}$ Computational Earth Science Group (EES-16) Los Alamos \\ National Laboratory
}

Salt formations are a commonly proposed for the permanent isolation of nuclear wastes due to their low water content and low permeability. Salt formations are mostly dry but they contain some residual water in the form of incusions, interganular water or water associated with accerssory mineral present in salt. Under ambient conditions brine associated to salt is not expected to move significantly after the closure of the repository. However, if heat generating waste is emplaced in salt, brine could be mobelised due to the heat gradient that is generated from the hot waste packages. There is a lack of acurate understanding of how much brine could be mobelized and the effetc thermal induced migration on brine composition.

Salt samples were collected from the Waste Isolation Pilot Plant (WIPP). Water content was examined via thermogravimetric analysis (TGA) and filter difference spectrometry (FDS) and salt core mineralogy characterized via energy dispersive X-Ray spectroscopy (SEM-EDS) and $\mathrm{X}$-ray diffraction (XRD). A profile of brine movement was also established as a function of temperature by subjecting salt crystals to a point heat source at one side of the salt. The behavior of the inclusions was recorded by capturing still images over time through a microscope equipped with a digital camera.

3D images of salt cores were also created by medical CT scans to map brine inclusions in larger core samples. Afterwards, cores were heated at variable temperatures and the released water captured for isotopic analysis $\left(\delta^{18} \mathrm{O}\right.$ and $\delta \mathrm{D})$ to determine source and age of the inclusion. A 3D map taken post-heating showed inclusion shifts and migration due the heating process. The results from this study demonstrate the significance of the different composition of salt inclusions on the thermally driven migration of water in future salt repositories. 